\title{
Pneumocystis Jirovecii Presenting as Nodular Pulmonary Opacities
}

\author{
Alan J. Hunter, $M D^{7}$ and David J. Steinhardt, $B A^{2}$ \\ 'Division of Hospital Medicine, Department of Medicine, Oregon Health \& Science University, Portland, OR, USA; ${ }^{2}$ School of Medicine, Oregon \\ Health \& Science University, Portland, OR, USA.
}

KEY WORDS: infection disease; HIV/AIDS; radiology; pulmonary diseases. $\mathrm{J}$ Gen Intern Med 31(7):814

DOI: $10.1007 / \mathrm{s} 11606-016-3618-1$

(c) Society of General Internal Medicine 2016

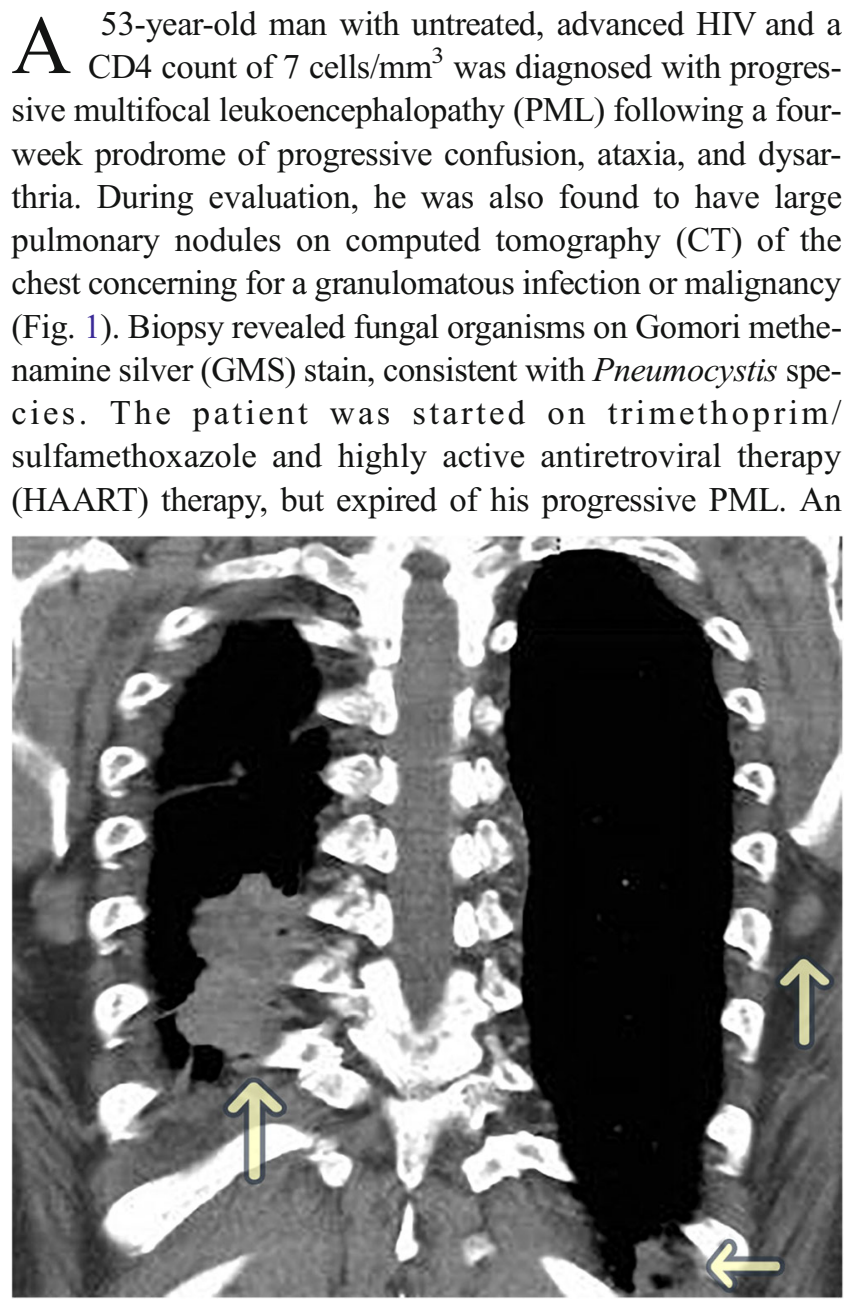

Figure 1. CT chest, abdomen, pelvis: multinodular, conglomerate pleural based mass of the right lower lobe and right lung base as well as two pleural based left nodules.

Received September 5, 2015

Revised December 11, 2015

Accepted February 1, 2016

Published online February 22, 2016 autopsy confirmed Pneumocystis jirovecii within the pulmonary nodules, but no malignancy (Fig. 2). In HIV patients, Pneumocystis jirovecii presents with bilateral interstitial ground-glass opacities in approximately $90 \%$ of patients. Additionally, atypical presentations are well described and may include cysts $(30 \%)$, lymphadenopathy (10\%), small or large nodules (5\%), and rarely consolidations or a spontaneous pneumothorax. ${ }^{1,2}$ Due to the wide range of radiologic findings associated with Pneumocystis jirovecii, diagnostic confirmation can be obtained via tissue biopsy. In a patient whose CD4 count is below 200 cells $/ \mathrm{mm}^{3}$, Pneumocystis jirovecii prophylaxis with trimethoprim/sulfamethoxazole is indicated regardless of diagnostic uncertainty. Clinicians should be aware of atypical presentations of Pneumocystis jirovecii, as they may be confused with malignancy, granulomatous processes, or other lung disease.

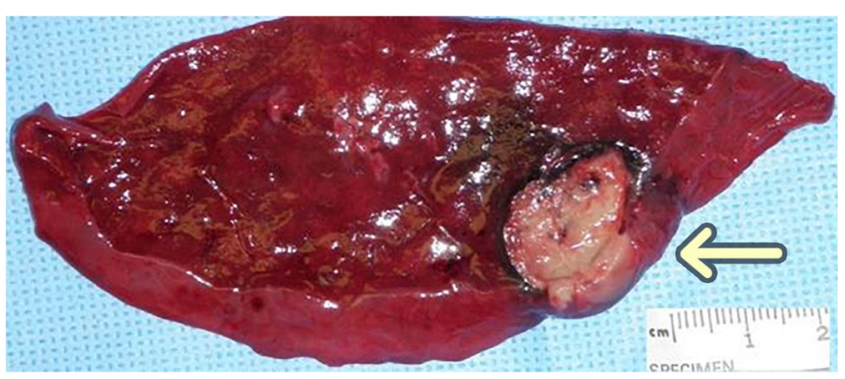

Figure 2. Lung biopsy (Autopsy): lung cavity contains necrotic material and copious microorganisms consistent with Pneumocystis.

Corresponding Author: Alan J. Hunter, MD; Division of Hospital Medicine, Department of Medicine Oregon Health Science University, 3181 SW Sam Jackson Park Rd, BTE 119, Portland, OR 97239-2997, USA (e-mail: huntera@ohsu.edu).

Compliance with Ethical Standards:

Conflict of Interest: The authors declare that they do not have a conflict of interest.

\section{REFERENCES}

1. Boiselle PM, Crans CA Jr, Kaplan MA. The changing face of Pneumocystis carinii pneumonia in AIDS patients. AJR Am J Roentgenol. 1999;172(5):1301-9.

2. Kanne JP, Yandow DR, Meyer CA. Pneumocystis jiroveci pneumonia: highresolution CT findings in patients with and without HIV infection. Am J Roentgenol. 2012;198:W555-61. 